\title{
PEMBELAJARAN SAINS DI SEKOLAH DASAR BERBASIS KURIKULUM 2013
}

\author{
Muslimin Ibrahim *
}

\begin{abstract}
Recently, 2013 curriculum is the best curriculum that have ever had for school in Indonesia. Based on the design, this curriculum comprehend in building human (students) and anticipate for the future. 2013 curriculum is the first curriculum that contain behavior or character explicitly as a competence that must be achieved and organize balancing act between students' soft skills and hard skill. In addition, Scoring of students' achievement in learning done comprehensively and continuity use many kinds of strategies that related with competence indicator that will be measured. The success of curriculum in reaching the mission is not only determined by the design, but the important thing is the implementation in the field; realizing the 2013 curriculum in schools. Special for learning science in elementary school must instruct to develop thinking skills and creativity. The teaching learning process focuses on scientific approach and integrated 4 component result study in 2013 curriculum, they are: spiritual attitude, social attitude, creativity, and knowledge. Special for attitude is not only taught verbally, but also by giving good example.
\end{abstract}

Keywords: Science Learning, 2013 Curriculum

\begin{abstract}
Abstrak
Sejauh ini, Kurikulum 2013 merupakan kurikulum terbaik yang pernah dimiliki sekolah di Indonesia. Berdasar rancangannya, kurikulum ini kompehensif dalam membangun manusia (siswa) dan antisipatif terhadap masa depan. Kurikulum 2013 merupakan kurikulum pertama yang secara eksplisit mencantum sikap/ karakter sebagai kompetensi yang harus dicapai dan mengatur perimbangan antara soft skills dan hard skills siswa. Selain itu, penilaian atas hasil belajar siswa dilakukan secara komprehensif dan berkesinambungan menggunakan berbagai strategi yang sesuai dengan indikator kompetensi yang akan diukur. Keberhasilan kurikulum dalam mencapai misi tidak hanya ditentukan oleh rancangan, tetapi yang lebih penting adalah implementasinya di lapangan, yaitu mewujudkan keunggulankeunggulan Kurikulum 2013 di Sekolah. Khusus untuk pembelajaran sains di Sekolah Dasar harus diarahkan untuk mengembangkan kemampuan berpikir dan kreativitas. Pembelajaran secara terpadu dan mengedepankan proses scientific approach serta mengintegrasi 4 komponen hasil belajar dalam Kurikulum 2013, yaitu sikap spiritual, sikap sosial, keterampilan, dan pengetahuan. Khusus untuk sikap tidak hanya diajarkan secara verbal, tetapi melalui contoh dan teladan.
\end{abstract}

Kata kunci : Pembelajaran Sains, Kurikulum 2013

* Muslimin Ibrahim adalah Kepala Pusat Pengembangan Pendidikan Dasar dan Menengah LPPM Universitas Negeri Surabaya 


\section{A. Pendahuluan}

Kurikulum 2013 telah dinyatakan berlaku meskipun masih terbatas pada sekolah-sekolah tertentu, tetapi secara bertahap semua sekolah di Indonesia akan menerapkan Kurikulum ini. Sejauh ini, Kurikulum 2013 merupakan kurikulum terbaik yang pernah dimiliki sekolah di Indonesia. Pernyataan ini bukanlah isapan jempol belaka. Terdapat beberapa pertimbangan untuk sampai kepada kesimpulan tersebut, khususnya mengenai elemen perubahan yang menonjol pada kurikulum tersebut dibandingkan dengan kurikulum yang sebelumnya.

Pertama: Kurikulum 2013 merupakan kurikulum pertama yang secara eksplisit mencantum sikap/karakter sebagai kompetensi yang harus dicapai. Di dalam kurikulum ini terdapat empat kompetensi inti, yaitu sikap spiritual, sikap sosial, keterampilan, dan pengetahuan. Dengan demikian kurikulum ini secara tertulis menginginkan pembangunan manusia Indonesia secara utuh.

Kedua: Berpuluh-puluh tahun yang lalu Leslie dan Briggs (1978) pernah menyatakan bahwa pembelajaran ilmu (science) yang terbaik, akan terjadi jika pembelajaran itu dilakukan sebagai mana ilmu itu ditemukan. Ilmu dibangun dan ditemukan lewat metode ilmiah. Pembelajaran yang dilaksanakan melalui metode ilmiah dikenal dengan pendekatan penelitian atau scientific approach (pendekatan sainstifik) atau pendekatan keterampilan proses. Pedoman pelaksanaan Kurikulum 2013 (Permendibud nomor 81A) menggarisbawahi pembelajaran mata pelajaran (mapel) berorientasi Kurikulum 2013 dilaksanakan menggunakan scientific approach ini.

Ketiga: tuntutan lapangan kerja akan lulusan program pendidikan adalah agar memiliki $80 \%$ soft skills dan $20 \%$ hard skills. Penelitian yang dilakukan oleh Dikti (2006) menemukan bahwa pembelajaran di sekolah justru terbalik, dilaksanakan $90 \%$ hard skills sementara soft skills hanya 10\%. Salah satu elemen perubahan pada Kurikulum 2013 adalah mengatur perimbangan antara soft skills dan hard skills ini.

Keempat: penilaian atas hasil belajar siswa dilakukan secara komprehensif dan berkesinambungan menggunakan berbagai strategi yang adekuat dengan indikator kompetensi yang akan diukur. Di samping penilaian menggunakan asesmen konvensional paper and pencil test, juga dilakukan menggunakan asesmen alternatif seperti penilaian autentik: tes kinerja, portofolio, penilaian hasil karya. Kurikulum 2013 mencakup standar penilaian yang melibatkan pertanyaanpertanyaandivergen yang tidak memiliki jawaban tunggal, memberi nilai bagi jawaban "nyeleneh", menilai proses pengerjaannya bukan hanya hasilnya, penilaian spontanitas/ ekspresif, dll (Nuh, 2013).

Perubahan-perubahan tersebut di atas menjadikan Kurikulum 2013 antisipatif terhadap masa depan. Kalau dibandingkan dengan keterampilan abad 21 yang diperlukan seseorang untuk berhasil hidup di masa depan, kurikulum 2013 sangat sesuai (Tabel 1).

Tabel 1 Perbandingan Tuntutan Kurikulum 2013 dengan Tuntutan Global

\section{Tuntutan Global $\left(21^{\text {st }}\right.$ century skills $)$}

\section{Tuntutan Kurikulum 2013}

\footnotetext{
Pengetahuan dasar (mengetahui): Pengetahuan: Pribadi yang menguasai ilmu literasi ICT, Penguasaan konten pengetahuan, teknologi, seni, budaya dan disiplin ilmu, Penguasaan lintas berwawasan kemanusiaan, kebangsaan, disiplin kenegaraan, dan peradaban
} 


\section{Tuntutan Global $\left(21^{\text {st }}\right.$ century skills $) \quad$ Tuntutan Kurikulum 2013}

Humanistic knowledge (menilai): Sikap: Pribadi yang beriman, berakhlak Kecakapan hidup/ kerja, kepedulian mulia, percaya diri, dan bertanggung jawab etika/ emosional, kompetensi budaya dalam berinteraksi secara efektif dengan lingkungan sosial, alam sekitar, serta dunia dan peradabannya

Metaknowledge (melakukan): kreatif/ inovatif, problemsolving/ berpikir kritis, komunikasi dan kolaborasi

Keterampilan: pribadi yang berkemampuan pikir dan tindak yang efektif dan kreatif dalam ranah abstrak dan konkret

Dari uraian di atas diperoleh bukti bahwa Kurikulum 2013 merupakan keputusan terbaik, karena berdasar rancangannya, kurikulum ini kompehensif dalam membangun manusia (siswa). Keberhasilan kurikulum dalam mencapai misi tidak hanya ditentukan oleh rancangan, tetapi yang lebih penting adalah implementasinya di lapangan.

\section{B. Bagaimana Mewujudkan Keunggulan-keunggulan Kurikulum 2013 di Sekolah Dasar?}

Implementasi Kurikulum 2013, dalam pembelajaran di kelas haruslah mempertimbangkan kondisi riil siswa dan pembelajaran yang terjadi di lapangan pada saat ini. Fakta tentang siswa kita di lapangan menurut Nuh (2013) hanya 5\% siswa Indonesia yang dapat mengerjakan soal-soal dalam katagori tinggi dan advance [memerlukan reasoning], sedangkan $71 \%$ siswa Korea sanggup. Dalam perspektif lain, $\mathbf{7 8 \%}$ siswa Indonesia hanya dapat mengerjakan soal-soal dalam katagori rendah [hanya memerlukan knowing, atau hafalan]. Hampir semua siswa Indonesia hanya menguasai pelajaran sampai level 3 saja, sementara negara lain banyak yang sampai level 4, 5, bahkan 6. Dengan keyakinan bahwa semua manusia diciptakan sama, interpretasi dari hasil ini hanya satu, yaitu: yang diajarkan di kelas berbeda dengan tuntutan zaman.

Temuan tersebut sejalan dengan hasil pengamatan lain yang menyatakan bahwa pembelajaran di sekolah berorientasi jangka pendek untuk mencapai keberhasilan dalam ujian akhir dan kompetensi menghafal. Pembelajaran sering dilakukan secara mekanistik latihan soal dengan drill. Perhatikan pembelajaran pada kelas terakhir (6 SD, 3 SMP, dan 3 SMA) semester 2. Pembelajaran dipandu oleh ujian.

Atas dasar pertimbangan di atas, pembelajaran sains SD berbasis kurikulum 2013 dilaksanakan sebagai berikut.

1. Pembelajaran di Sekolah Dasar harus diarahkan untuk mengembangkan kemampuan berpikir. Pengembangan kemampuan berpikir sejak dini ini dilakukan dengan pertimbangan bahwa kemampuan berpikir seseorang ditentukan oleh kompleksitas jaringan otaknya. Jaringan otak yang terdiri dari neuron (sel saraf) terbentuk dan berkembang sangat cepat pada usia muda. Keterampilan berpikir yang dikembangkan tidak hanya kemampuan berpikir tingkat rendah yang digunakan untuk pekerjaan rutin, tetapi juga kemampuan berpikir tingkat tinggi yang digunakan untuk pengambilan keputusan, penyelesaian masalah dan sebagainya [Center on the Developing Child, Harvard University, 2011]. Pembelajaran dilakukan melalui mencari tahu, bukan diberitahu. 
2. Penekanan kedua pembelajaran di SD adalah mengembangkan kemampuan kreatif,karena menurut Nuh (2013) yang mengutip pendapat Dyers, J.H. et.al (2011), 2/3 kemampuan kreatif diperoleh seseorang dari pendidikan dan hanya $1 / 3$ saja dari bakat. Pembelajaran yang sesuai untuk mengembangkan kemampuan kreatif adalah melalui: Observing [mengamati], Questioning [menanya], Associating [menalar], Experimenting [mencoba], Networking [Membentuk jejaring]. Siswa dibiasakan untuk bekerja dalam jejaringan melalui collaborative learning. Agar siswa berani berlaku kreatif, menurut Sharp. C (2004), guru harus secara sengaja melakukan pembelajaran dengan memberikan tugas-tugas yang tidak hanya memiliki satu jawaban tertentu yang benar [banyak/semua jawaban benar], menekankan pada proses bukan hanya hasil, memberanikan peserta didik untuk mencoba, untuk menentukan sendiri yang kurang jelas/lengkap informasinya, untuk memiliki interpretasi sendiri terkait dengan pengetahuan atau kejadian yang diamatinya.

3. Mengedepankan proses scientific approach mengamati, menanya, menalar, menyimpulkan sampai memutuskan sehingga peserta didik sejak kecil sudah terlatih dalam berpikir tingkat tinggi yang nantinya diperlukan untuk pengambilan keputusan;

4. Pembelajaran dilaksanakan dengan mengintekrasi 4 komponen hasil belajar dalam Kurikulum 2013, yaitu sikap spiritual, sikap sosial, keterampilan, dan pengetahuan.

5. Standar Proses yang semula terfokus pada Eksplorasi, Elaborasi, dan Konfirmasi dilengkapi dengan Mengamati, Menanya, Mengolah, Menalar, Menyajikan, Menyimpulkan, dan Mencipta;

6. Belajar tidak hanya terjadi di ruang kelas, tetapi juga di lingkungan sekolah dan masyarakat;

7. Guru bukan satu-satunya sumber belajar;

8. Sikap tidak hanya diajarkan secara verbal, tetapi melalui contoh dan teladan;

9. Tematik dan terpadu.

Berikut ini diberikan beberapa contoh alternatif implementasi pembelajaran sains di sekolah dasar.

\begin{tabular}{|c|c|c|c|}
\hline \multicolumn{4}{|c|}{$\begin{array}{l}\text { Alternatif-1: Mengintegrasikan SA dengan konten dan sikap melalui pembiasaan } \\
\text { Langkah }\end{array}$} \\
\hline $\begin{array}{l}\text { Scientific } \\
\text { Approach }\end{array}$ & Bentuk Kegiatan & Contoh & $\begin{array}{c}\text { Hasil Belajar } \\
\text { yang diharapkan }\end{array}$ \\
\hline Mengamati & $\begin{array}{l}\text { Guru menyajikan } \\
\text { fenomena untuk } \\
\text { memotivasi, } \\
\text { apersepsi, dan } \\
\text { memunculkan } \\
\text { masalah }\end{array}$ & $\begin{array}{l}\text { Kepada siswa ditunjukkan pohon dan } \\
\text { dun bergoyang karena hembusan } \\
\text { angina, rumah roboh dan pohon } \\
\text { tumbang. Siswa dimotivasi untuk dapat } \\
\text { mengajukan masalah, misalnya lewat } \\
\text { pertanyaan membimbing: } \\
\text { Pernahkah merasakan angin }\end{array}$ & $\begin{array}{l}\text { Mengaitkan apa } \\
\text { yang diketahui } \\
\text { dengan informasi } \\
\text { baru } \\
\text { Keterampilan } \\
\text { berpikir, } \\
\text { merumuskan }\end{array}$ \\
\hline
\end{tabular}




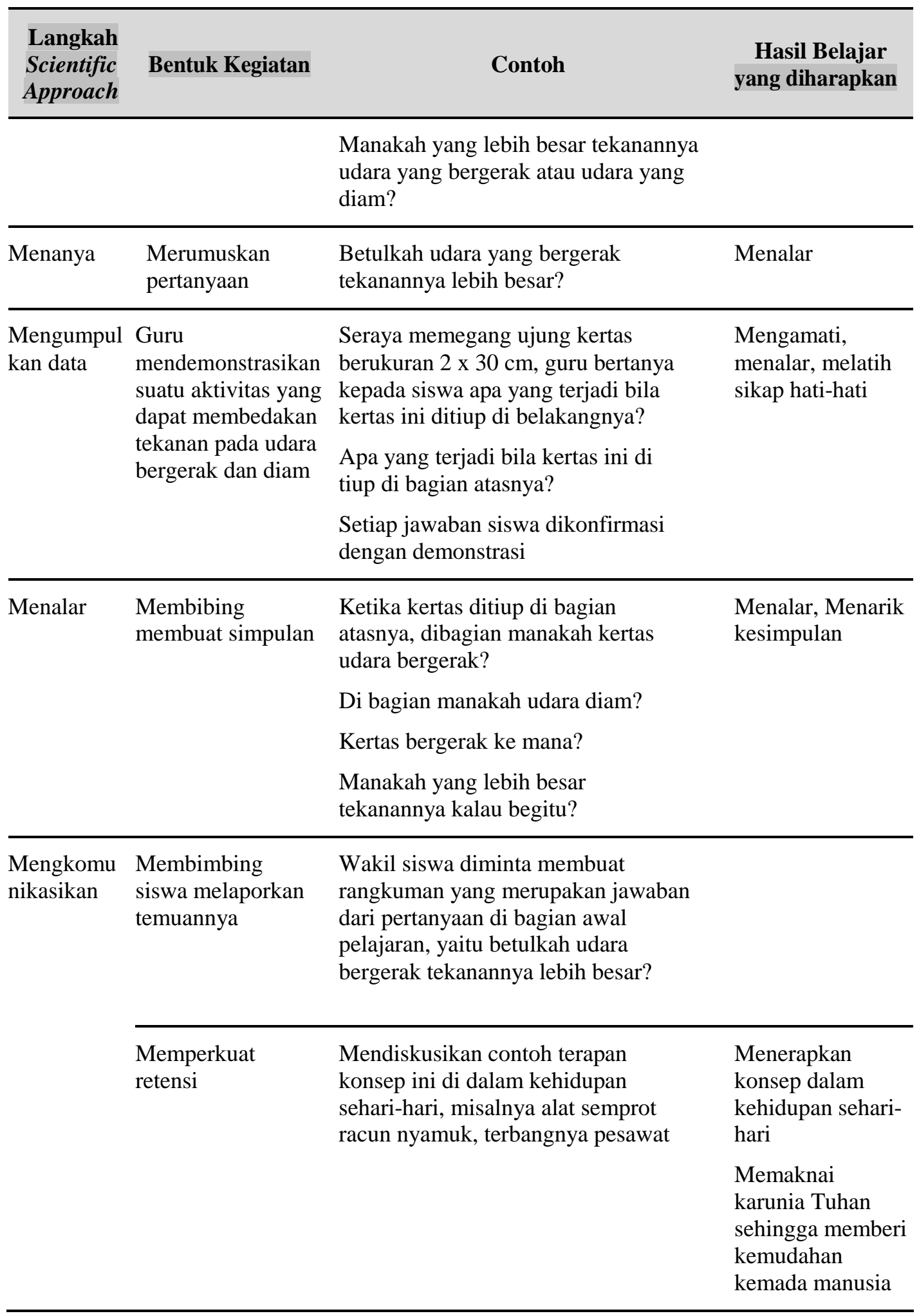


6 | Premiere Educandum, Volume 4 Nomor 1, Juni 2014, 1-9

\section{Alternatif-2: Mengintegrasikan SA dengan konten dan sikap melalui Contoh (pemodelan)}

Kerangka berpikir model pemaknaan:
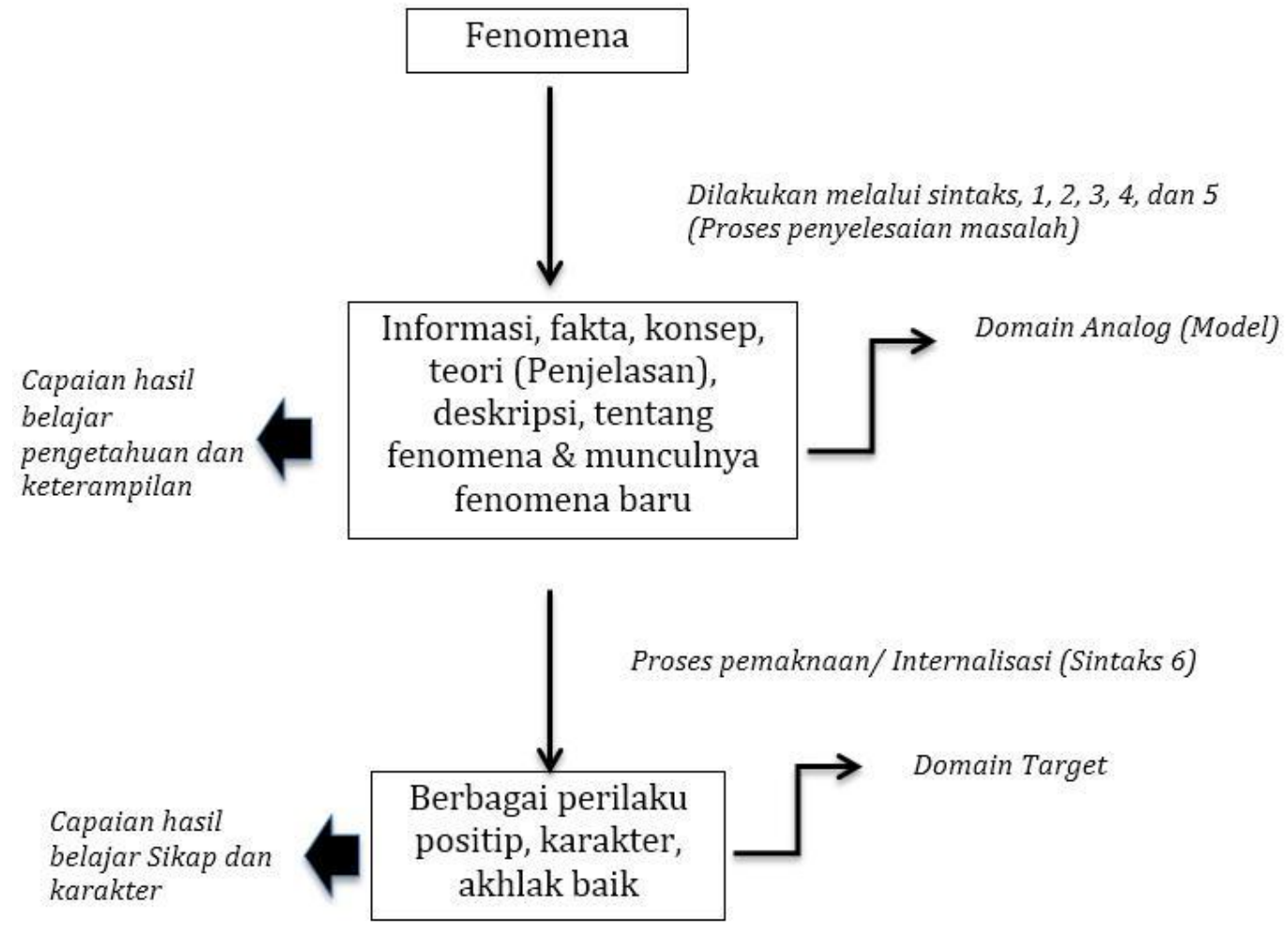

Gambar 1 Alur Berpikir Model Pemaknaan (Ibrahim, 2014)

Pada alternatif ini, pemahan konsep sains, keterampilan proses, dan sikap dibangun secara simultan.

Tahap pertama : siswa mengeskplorasi alam menggunakan scientific approach, sehingga mereka membuat temuan (konsep, prosedur, informasi, penjelasan, bahkan hukum meskipun hanya baru bagi siswa). Tahap ini memberi penekanan pada membangun hard skills

Tahap kedua : fenomena alam yang ditemukan pada tahap pertama dijadikan model perilaku positif. Tugas guru pada tahap ini adalah menunjukkan kepada siswa bahwa semua gejala alam yang tampak adalah bahan renungan, karena mengandung tamsil, ibarat, dan contoh-contoh. Guru menunjukkan bukti-bukti dan penguatnya. Dengan perkataan lain pada tahap ini guru menunjukkan model sikap/karakter agar dapat ditiru oleh siswa. Pada tahap ini guru membangun soft skills Sebagai ilustrasi pembelajaran tentang metamorphosis pada kupu-kupu.

Bagian pertama : Siswa mengamati telur, kemudian menetas menjadi ulat, mengamati perlaku ulat, selanjutnya mengamati bagaimana ulat berubah menjadi keponpong, mengamati perilaku 
kepompong, dan mengamati bagaomana sulitnya kupu-kupu keluar dari kepompong melalui lubang yang sempit, terakhir mengamati bagaimana indahnya kupu-kupu, makanan kupukupu yang hanya nectar bunga. Dari pengamatan ini siswa menemukan informasi tentang

- Nama-nama tahapan metamorphosis pada kupu-kupu

- Waktu yang diperlukan untuk perkembangan tiap-tiap tahapan

- Karakteristik dan sifat-sifat setiap tahapan

- Konsep metamorphosis sempurna

Bagian kedua : temuan pada bagian pertama di atas, dijadikan model untuk perilaku (sikap) menggunakan stategi analogi. Temua sebagai base domain (model) dan perilaku (sikap) sebagai target domain. Antara kedua domain ini memiliki persamaan, guru menunjukkan persamaan itu.

\begin{tabular}{|c|c|c|}
\hline $\begin{array}{c}\text { Base Domain } \\
\text { (Hasil Pengamatan }) \\
\text { Konsep } \\
\text { Metamorfosis }\end{array}$ & $\begin{array}{l}\text { Hasil Pengamatan/ Pena- } \\
\text { Laran/ Diskusi }\end{array}$ & $\begin{array}{c}\text { Target Domain (Perilaku Positif } \\
\text { yang Harus Dibangun }\end{array}$ \\
\hline Ulat (Larva) & $\begin{array}{l}\text { Perilaku rakus, memakan segala } \\
\text { macam dedunan, mendatangkan } \\
\text { kerugian bagi petani, menjijikkan }\end{array}$ & $\begin{array}{l}\text { Perilaku negatif rakus yang harus } \\
\text { dihindari }\end{array}$ \\
\hline \multirow[t]{2}{*}{ Kepompong } & $\begin{array}{l}\text { Tidak makan, mengurung diri di } \\
\text { dalam cocoon, merupakan proses } \\
\text { pengendalian diri, berpuasa }\end{array}$ & $\begin{array}{l}\text { Pengendalian diri, berpuasa perlu } \\
\text { dilakukan.(Lihat QS: 2:183) }\end{array}$ \\
\hline & $\begin{array}{l}\text { Kupu-kupu keluar dari } \\
\text { kepompong melalui lubang kecil, } \\
\text { sehingga sangat sulit. Jika lubang } \\
\text { diperbesar, justru kupu2 tidak } \\
\text { bias terbang karena sayapnya } \\
\text { lemah. Ternyata lubang kecil } \\
\text { adalah cara Tuhan untuk } \\
\text { menekan cairan tubuh kupu-kupu } \\
\text { agar masuk ke sayap sehingga } \\
\text { membuat sayap menjadi kuat. } \\
\text { Pada gilirannya dapat terbang }\end{array}$ & $\begin{array}{l}\text { Sikap sabar menjalani cobaan } \\
\text { merupakan perilaku yang harus } \\
\text { dipupuk, dengan menanam } \\
\text { pemahaman bahwa janji Tuhan } \\
\text { pasti benar, yaitu setelah kesulitan } \\
\text { pasti ada kemudahan (Lihat QS: } \\
\text { 94: 5-6) dan mengangun etos kerja, } \\
\text { agar siswa selalu tekun bekerja } \\
\text { samapai selesai dan setelah selesai } \\
\text { dilanjutnya dengan mengerjakan } \\
\text { pekerjaan yang baru (QS: 94: 7) }\end{array}$ \\
\hline $\begin{array}{l}\text { Kupu-kupu } \\
\text { Dewasa (Imago) }\end{array}$ & $\begin{array}{l}\text { Tubuhnya indah berwarna warni } \\
\text { sangat menarik, kalau makan } \\
\text { hanya makanan terpilih yaitu sari } \\
\text { pati bunga (nectar), kalau hingga } \\
\text { tidak menggoyangkan dahan }\end{array}$ & $\begin{array}{l}\text { Perilaku baik ditunjukkan dengan } \\
\text { kesediaan mengikatkan diri pada } \\
\text { perbuatan baik, menjaga makanan } \\
\text { hanya yang halal dan toyib, kalau } \\
\text { bergaul tidak mendatangkan } \\
\text { kesusahan bagi orang lain }\end{array}$ \\
\hline
\end{tabular}

Fenomena alam yang ditemukan oleh siswa tidak pernah habis dan fenomena alam tersebut semuanya merupakan tamsil dan ibarat bagi orang-orang yang mau berpikir (QS: 3,190). 
8 | Premiere Educandum, Volume 4 Nomor 1, Juni 2014, 1-9

\section{Penutup}

Dengan demikian pembelajaran sains di SD secara sengaja dirancang untuk mengajar konsep sains, proses sains, dan sikap baik sosial maupun spiritual. Merancang pembelajaran yang demikian secara sengaja merupakan tuntutan kurikulum 2013 karena di dalam kurikulum tersebut secara eksplisit menuntut KI-1, KI-2, KI-3, dan KI-4.

Karena kurikulum menuntut keempat hasil belajar itu secara eksplisit dan guru secara eksplisit pula merancang pembelajaran yang mengintegrasikan kegiatan untuk mencapai keempatnya, pada gilirannya instrumen penilaian harus dikembangkan untuk mengases keempat hasil belajar tersebut. Oleh karena itu asesmen alternative di samping asesmen konvensional paper and pencil perlu pula diimplementasikan oleh guru. 


\section{DAFTAR RUJUKAN}

Al-Qur'an Al Karim

Dweck, Carol S. 2008.Mindset, The New Psychology of Succes: How we can learn to fulfill our Potentials. New York: Ballantine Books.

Ibrahim, Muslimin. "Dimensi Pendidikan dan Budi Pekerti di dalam Model-model Biologi (Pidato Pengukuhan dalam rangka penerimaan Jabatan Guru Besar 1 Juli 2001), Sang Profesor Kumpulan Pidato Pengukuhan Guru Besar. Surabaya: University Press, 2011 ISBN 978-979-028-459-3.

Ibrahim, Muslimin, dkk (2008). Pengembangan Model Pembelajaran Inovatif untuk Mengembangkan sikap positif, kemampuan berpikir, dan hasil belajar kognitif melalui Pelajaran IPA. Penelitian Inovatif Nasional yang dibiayai oleh Puslitjaknov Balitbang Depdiknas. Jakarta: Badan Penelitian dan Pengembangan Depdiknas- Pusat Penelitian Kebijakan dan Inovasi.

Ibrahim, Muslimin, Suhartono, Suyono, (2009). Pengembangan Perangkat Pembelajaran Inovatif Melalui Pemaknaan dalam Mapel IPA dan Bahasa. Penelitian Strategis Nasional dibiayai oleh Direktorat Jenderal Pendidikan tinggi.

Ibrahim, Muslimin, Wahyu Sukartiningsih. (2012, 2013, dan 2014). Pemberdayaan Siswa Sekolah Dasar Untuk Berperilaku Positif Dan Berkemampuan Berpikir Melalui Pengembangan Perangkat Dan Diseminasi Pembelajaran Berorientasi Pemaknaan. Penelitian Hibah Bersaing Pascasarjana Dibiayai oleh Dir. LitabmasDepdikbud.

Ibrahim, Muslimin, (2014a). Inovasi Pembelajaran Sains dalam Implementasi Kurikulum 2013. Makalah disampaikan pada Seminar Nasional Pendidikan Sains yang dilaksanakan oleh Program Pascasarjana Universitas Negeri Surabaya, tanggal 18 Januari 2014.

Ibrahim, Muslimin. (2014b). Model Pembelajaran Melalui Pemaknaan (Draft Final). Diterbitkan sebagai produk penelitian berkelanjutan tentang Model Pemaknaan 2008 - 2014.

Kementerian Pendidikan dan Kebudayaan Republik Indonesia. (2013). PermendikbudNomor 81A/ 2013 Tentang Pedoman Pelaksanaan Kurikulum 2013, Lampiran IV. 